\title{
Enhanced Cycling and Rate Capability by Epitaxially Matched Conductive Cubic TiO Coating on $\mathrm{LiCOO}_{2}$ Cathode Films
}

\author{
Deepak P. Singh,* Yorick A. Birkhölzer, Daniel M. Cunha, Thijs Dubbelink, Sizhao Huang, \\ Theodoor A. Hendriks, Caroline Lievens, and Mark Huijben*
}

Cite This: ACS Appl. Energy Mater. 2021, 4, 5024-5033

Read Online

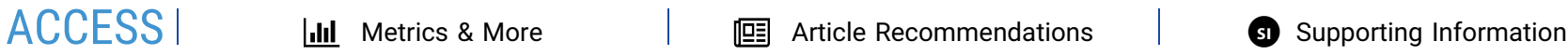

ABSTRACT: Layered lithium transition-metal oxides, such as $\mathrm{LiCoO}_{2}$ and its doped and lithium-rich analogues, have become the most attractive cathode material for current lithiumion batteries due to their excellent power and energy densities. However, parasitic reactions at the cathode-electrolyte interface, such as metal-ion dissolution and electrolyte degradation, instigate major safety and performance issues. Although metal oxide coatings can enhance the chemical and structural stability, their insulating nature and lattice mismatch with the adjacent cathode material can act as a physical barrier for ion transport, which increases the chargetransfer resistance across the interface and impedes cell performance at high rates. Here, epitaxial engineering is applied to stabilize a cubic (100)-oriented $\mathrm{TiO}$ layer on top of single (104)-oriented $\mathrm{LiCoO}_{2}$ thin films to study the effect of a conductive coating on the electrochemical performance. Lattice matching between the (104) $\mathrm{LiCoO}_{2}$ surface facets and the (100) $\mathrm{TiO}$ plane enables the formation of the titanium mono-oxide phase, which dramatically enhances the cycling stability as well as the rate capability of $\mathrm{LiCoO}_{2}$. This cubic

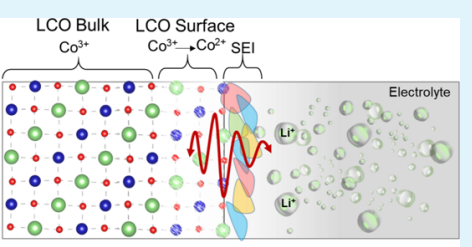

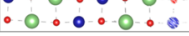

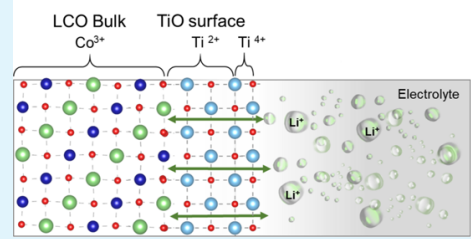
$\mathrm{TiO}$ coating enhances the preservation of the phase and structural stability across the (104) $\mathrm{LiCoO}_{2}$ surface. The results suggest a more stable $\mathrm{Co}^{3+}$ oxidation state, which not only limits the cobalt-ion dissolution into the electrolyte but also suppresses the catalytic degradation of the liquid electrolyte. Furthermore, the high c-rate performance combined with high Columbic efficiency indicates that interstitial sites in the cubic TiO lattice offer facile pathways for fast lithium-ion transport.

KEYWORDS: $\mathrm{LiCoO}_{2}$ epitaxial thin film, cubic titanium oxide, interface engineering, lithium transport

\section{INTRODUCTION}

As society is transiting toward sustainable and emission-free mobility, demands have risen for batteries with improved energy and power capacities, combined with enhanced safety and extended cycle life. Therefore, layered lithium transitionmetal oxides (such as $\mathrm{LiCoO}_{2}$ and its doped and lithium-rich analogues), exhibiting excellent power and energy densities, have become the best cathode material for current lithium-ion batteries used in a wide variety of applications ranging from thin-film micro-batteries to large-scale traction batteries. ${ }^{1}$ However, the electrochemical performance of these layered transition-metal oxides is intrinsically limited by the lattice distortions from a hexagonal phase to a monoclinic phase during repetitive charge-discharge cycling and the detrimental anionic reactions under overcharging conditions. ${ }^{2-5}$ As overcharging introduces lithium vacancies in the two-dimensional transition-metal layers, it leads to an order/disorder phase transition. ${ }^{6,7}$ This continuous phase transition causes a gradual oxygen loss from the cathode material, which in turn deteriorates the electrochemically active phases and corresponding kinetic properties over extensive cycling. ${ }^{8}$ This loss of oxygen changes the valence state of the cobalt atoms from $\mathrm{Co}^{3+}$ to $\mathrm{Co}^{2+}$ at the cathode-electrolyte interface, resulting in parasitic reactions, such as metal-ion dissolution and electrolyte degradation, ${ }^{9,10}$ which instigate major safety and performance issues. $^{7,11,12}$

To overcome these inherent issues in $\mathrm{LiCoO}_{2}$-type cathode materials, various strategies have been explored, including nanostructuring, ${ }^{13,14}$ crystal engineering, ${ }^{15-17}$ cation doping, ${ }^{18}$ surface coating, ${ }^{19,20}$ and electrolyte additives. ${ }^{21,22}$ Thus far, the application of a thin-film coating on the surface of the active cathode material has turned out to be the most successful strategy to limit the cathode-electrolyte reactivity and to enhance the cycle life of the battery. ${ }^{23,24}$ These metal oxide coatings (e.g., $\mathrm{Al}_{2} \mathrm{O}_{3}, \mathrm{TiO}_{2}, \mathrm{ZrO}_{2}$, or $\mathrm{SiO}_{2}$ ) are believed to form a solid solution interphase layer (e.g., $\mathrm{LiAl}_{x} \mathrm{Co}_{1-x} \mathrm{O}_{2}$ for $\mathrm{Al}_{2} \mathrm{O}_{3}$ coating) at the surface of the layered transition-metal oxide, which will passivate the cathode surface and enhance the interfacial kinetics for lithium transport. ${ }^{25,26}$ Furthermore, it

Received: February 28, 2021

Accepted: April 19, 2021

Published: April 29, 2021 
was also suggested that such coatings mitigate the order/ disorder transition and oxygen losses from the cathode lattice as well as other parasitic reactions, such as HF evolution due to electrolyte decomposition and the irreversible growth of solid electrolyte interphase (SEI) layers. ${ }^{5,19,27-29}$ However, the exact nature and contribution of these surface coatings are not fully understood and still under debate. ${ }^{24}$

Another strategy to enhance the cycle life and safety of lithium-ion batteries is to combine successful $\mathrm{LiCoO}_{2}$-type cathode materials with a solid electrolyte. Although solid electrolytes are inherently safer as compared to liquid electrolytes, their limited stability against such high-voltage cathode materials remains a major bottleneck. ${ }^{30-32}$ Furthermore, the combination of anisotropic lithium transport in such layered $\mathrm{LiCoO}_{2}$-type materials, slow lithium diffusion within many solid electrolytes, and the incremental formation of a space charge layer across the cathode-electrolyte solid-solid interface limits such all-solid-state battery concepts for usage in large-scale and high-power applications. ${ }^{32-34}$ Interestingly, previous studies have shown that a heterogeneous interfacial coating at the solid-solid cathode-electrolyte interface can suppress the mixed electronic state and improve the lithium diffusion behavior. ${ }^{32,35-38}$

Although metal oxide coatings on cathode materials enhance the chemical and structural stability of liquid- and solidelectrolyte-based battery systems, these coatings are intrinsically electrically insulating (e.g., $\mathrm{Al}_{2} \mathrm{O}_{3}, \mathrm{TiO}_{2}, \mathrm{ZrO}_{2}$, or $\mathrm{SiO}_{2}$ ) and commonly exhibit a lattice mismatch with the adjacent cathode material. This lattice mismatch between the crystal structures of the cathode and coating materials can act as a physical barrier for ion transport, which increases the chargetransfer resistance across the interface and impedes the overall cell performance. ${ }^{33,39-41}$

Epitaxial engineering can be used to control the crystal orientation within thin-film model systems, which enables a unique insight into the relation between electrochemistry and crystal directionality of such chemically complex interfaces, not obtainable in single crystals or polycrystalline samples. Previous thin-film studies have demonstrated the optimization of lithium transport for epitaxial $\mathrm{LiCoO}_{2}$-type cathode systems by controlling the specific crystal orientation of the facets [e.g., (001), (110), or (104)] at the interface toward the electrolyte. $^{42-45}$ Although these crystal facets exhibit the lowest surface energy among all nonpolar and electrochemical active facets, the multiple electronic states at the surface govern their reaction kinetics with the electrolyte and dominate their electrochemical performance. ${ }^{38,46,47}$ Therefore, metal oxide coatings still play an important role in improving the electrochemical performance of $\mathrm{LiCoO}_{2}$-type thin-film model systems. Many thin-film studies have investigated the effect of an additional amorphous or polycrystalline coating; however, only a few studies have explored the impact of an epitaxially matched layer $\left(\mathrm{ZrO}_{2}, \mathrm{BaTiO}_{3}\right)$ on the surface of a highly crystalline $\mathrm{LiCoO}_{2}$ thin film. ${ }^{24,48}$ Therefore, a large knowledge gap currently exists in how the alignment of the crystal structures across such epitaxial coating-cathode interface can enhance lithium transport while preventing parasitic reactions with the adjacent electrolyte.

In this study, we focus on the epitaxial engineering of an ionic and electronic conducting $\mathrm{TiO}_{x}(x=0.7-1.25)$ coating at the interface with a single-oriented $\mathrm{LiCoO}_{2}$ thin film. The cubic $\mathrm{TiO}$ phase consists of approximately $15 \%$ randomly arranged cation and anionic vacancies in a defect rock salt structure and typically exhibits metallic behavior. ${ }^{49-52}$ Furthermore, such oxygen vacancies in oxide materials have shown enhanced lithium transport and storage properties. $^{47,53-55}$ The cubic titanium mono-oxide $(\mathrm{TiO})$ is normally stabilized under high temperature and pressure conditions, ${ }^{50}$ while in our case, the lattice matching with the underlying (104) $\mathrm{LiCoO}_{2}$ crystal facet has enabled us to realize a full epitaxial thin-film model system. Detailed analysis in a half cell against lithium metal has shown dramatic enhancement of the cycling stability as well as the rate capability. The improved electrochemical performance and preservation of the phase and structural stability across the (104) $\mathrm{LiCoO}_{2}$ surface suggest a more stable $\mathrm{Co}^{3+}$ oxidation state, which not only limits the cobalt-ion dissolution into the electrolyte but also suppresses the catalytic degradation of the liquid electrolyte. The high crate performance combined with high Columbic efficiency indicates that interstitial sites in the cubic $\mathrm{TiO}$ lattice offer facile pathways for fast lithium-ion transport.

\section{EXPERIMENTAL SECTION}

The $\mathrm{LiCoO}_{2}$ thin films are deposited on metallic $\mathrm{SrRuO}_{3}$ buffer layers, which enhances the electrical transport toward the underlying conducting substrates. ${ }^{43}$ The $\mathrm{LiCoO}_{2}$ and $\mathrm{SrRuO}_{3}$ layers were grown by pulsed laser deposition (PLD) on Nb-doped (0.5 wt \%) single-crystalline $\mathrm{SrTiO}_{3}[(100),(110)$, or (111)] substrates from sintered $\mathrm{LiCoO}_{2}\left(40 \%\right.$ excess of lithium) and $\mathrm{SrRuO}_{3}$ targets, using a $\mathrm{KrF}$ excimer laser operating at $248 \mathrm{~nm}$. The $\mathrm{Nb}-\mathrm{SrTiO}_{3}$ substrates were pre-annealed at $950{ }^{\circ} \mathrm{C}$ for $1.5 \mathrm{~h}$ in an oxygen flow of $150 \mathrm{~mL} /$ min. The laser energy fluence was $2.3 \mathrm{~J} \mathrm{~cm}^{-2}$ for the growth of both $\mathrm{LiCoO}_{2}$ and $\mathrm{SrRuO}_{3}$. The temperature (and oxygen pressure) during $\mathrm{SrRuO}_{3}$ and $\mathrm{LiCoO}_{2}$ growth were, respectively, $600{ }^{\circ} \mathrm{C}(0.13 \mathrm{mbar})$ and $800{ }^{\circ} \mathrm{C}(0.23 \mathrm{mbar})$. In total, 3600 pulses at $2 \mathrm{~Hz}$ were used to deposit the $\mathrm{SrRuO}_{3}$ layer and 7200 pulses at $20 \mathrm{~Hz}$ for the $\mathrm{LiCoO}_{2}$ layer. Under these growth conditions, the thicknesses of the $\mathrm{SrRuO}_{3}$ and $\mathrm{LiCoO}_{2}$ layers are, respectively, about 60 and $120 \mathrm{~nm} .{ }^{56}$ After deposition, the films were cooled down to room temperature under 1 bar oxygen pressure at $10{ }^{\circ} \mathrm{C} \mathrm{min}-1$ to enhance the oxidation level. For the deposition of an additional $\mathrm{TiO}$ thin film, a sintered anatase $\mathrm{TiO}_{2}$ target was ablated for 1800 pulses at $5 \mathrm{~Hz}$, resulting in a layer thickness of about $30 \mathrm{~nm}$, which is similar to thicknesses of surface coatings in previous $\mathrm{LiCoO}_{2}$ studies. ${ }^{57-59}$ The cubic $\mathrm{TiO}$ thin film was realized on a (104)-oriented $\mathrm{LiCoO}_{2}$ film at a temperature of 550 ${ }^{\circ} \mathrm{C}$ and $0.01 \mathrm{mbar}$ argon pressure. After deposition, the thin films were cooled down to room temperature under $0.01 \mathrm{mbar}$ argon pressure at $10{ }^{\circ} \mathrm{C} \mathrm{min}{ }^{-1}$ to maintain the oxidation level in the deposited layers.

The crystal structure, surface morphology, and thin-film thickness were investigated by X-ray diffraction (XRD, PANalytical X'Pert PRO), Raman spectroscopy (WiTec), and atomic force microscopy (AFM, Bruker ICON Dimension Microscope). The lithium content in the $\mathrm{LiCoO}_{2}$ thin films was measured using inductively coupled plasma-optical emission spectroscopy (ICP-OES, PerkinElmer $8300 \mathrm{dv}$ ) in which the plasma was inspected vertically with respect to the detector using the radial viewing mode.

High-resolution XRD data were collected post cycling using a Bruker D8 Discover diffractometer with a high brilliance microfocus $\mathrm{Cu}$ rotating anode generator (TXS, $2.5 \mathrm{~kW}$ ), hybrid Montel optics (parallel-focusing), a channel-cut two-bounce $\mathrm{Ge}(220)$ monochromator (ACC2), a $1 \mathrm{~mm}$ diameter circular pinhole beam collimator, and an EIGER2 R $500 \mathrm{~K}$ area detector. A coupled scan was performed by operating the detector in the conventional $0 \mathrm{D}$ mode with a small region of interest $\left(13 \times 61\right.$ pixels, pixel size $\left.75 \times 75 \mu \mathrm{m}^{2}\right)$. No secondary optics in the diffracted beam paths between sample and detector were installed. During scans, the intensity of the incident beam is automatically adjusted by a multilevel rotary absorber to optimize the effective dynamic range of each measurement and to avoid detector saturation. Raw data for the symmetrical and asymmetrical reciprocal space maps (RSMs) of various Bragg 
(a)

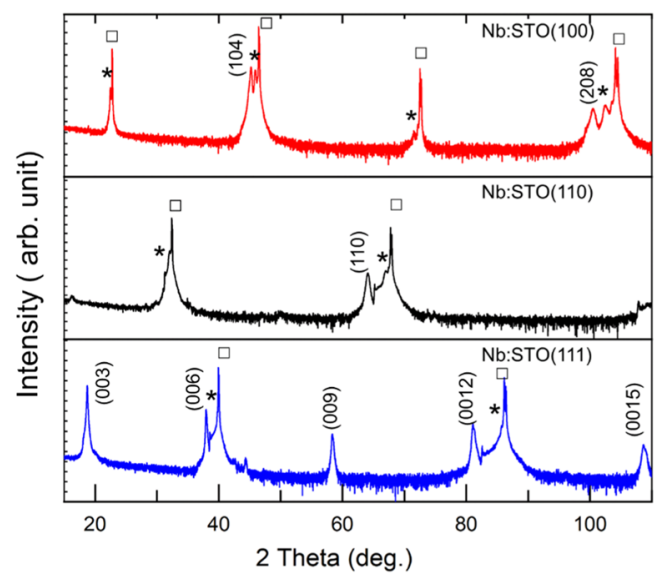

(b)

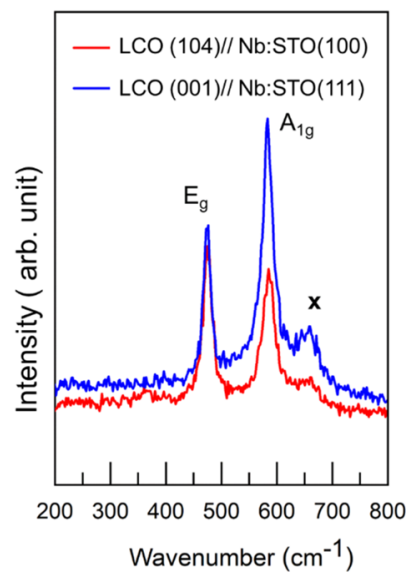

Figure 1. Out-of-plane XRD pattern of $\mathrm{LiCoO}_{2}$ epitaxial thin films grown on $\mathrm{SrRuO}_{3}$-buffered $\mathrm{Nb}-\mathrm{SrTiO}_{3}(\mathrm{Nb} / \mathrm{STO})$ substrates with different crystal orientations: (100), (110), and (111). Nb/SrTiO 3 and $\mathrm{SrRuO}_{3}$ peaks are indicated by $\square$ and * symbols, respectively. (b) Raman spectra of LCO thin films epitaxially grown in (104) and (001) orientations.

reflections were collected via sets of high-resolution rocking curves for which the detector was operated in the stationary $2 \mathrm{D}$ snapshot mode in a grazing-exit configuration. In our unique lab-based XRD system, the combination of high beam collimation to a virtual point source in combination with a large area detector enables us to reconstruct the full 3D reciprocal space around the chosen Bragg reflections. Angular to reciprocal space conversion was done according to He. ${ }^{60}$ Subsequently, the array of 3D reciprocal space coordinates with the corresponding scattering intensities was binned and interpolated onto an orthogonal and equidistant 3D matrix with voxel size $q_{x}, q_{y}, q_{z}=$ $0.0005 \AA^{-1}$. The effective resolution is furthermore limited by the convolution of the aforementioned voxel size and the experimental accuracy. An ideal, asymmetrical RSM contains in-plane and out-ofplane information about the substrate and all thin-film layers simultaneously, that is, in one picture. In coplanar geometry, the (103) and (113) reflections of the cubic $\mathrm{SrTiO}_{3}(001)$ substrate are commonly investigated, but we confirmed that the adjacent regions in reciprocal space do not contain (strong) reflections of both $\mathrm{LiCoO}_{2}$ and $\mathrm{TiO}$. The selection of a suitable region in reciprocal space is complicated by the dissimilar crystal structures of the substrate and the layers of interest. While $\mathrm{Nb} / \mathrm{SrTiO}_{3}$ and $\mathrm{SrRuO}_{3}$ are perovskites, $\mathrm{LiCoO}_{2}$ has a hexagonal layered structure, and $\mathrm{TiO}$ has a defect rock salt structure.

For electrochemical characterization, the films were transferred to an argon atmosphere glovebox $\left(<0.1 \mathrm{ppm} \mathrm{H}_{2} \mathrm{O}\right.$ and $\left.\mathrm{O}_{2}\right)$ and placed on a hotplate for $\sim 10 \mathrm{~min}$ at $125{ }^{\circ} \mathrm{C}$ to remove any water content. Subsequently, they were positioned in an electrochemical EC-Ref cell (EL-CELL) and combined with a glass fiber separator of $1 \mathrm{~mm}$ thickness, $100 \mu \mathrm{L}$ electrolyte with $1 \mathrm{M} \mathrm{LiPF}_{6}$ in $1: 1$ ethylene carbonate/dimethyl carbonate (EC/DMC), and a lithium metal anode. The electrochemical measurements were performed at room temperature using a BioLogic VMP-300 system in a two-electrode setup. Galvanostatic charge-discharge cycling was performed within $3.5-4.2 \mathrm{~V}$ range to avoid any contributions of structural or phase transitions on the cycle performance for higher voltages, as previously demonstrated for $\mathrm{LiCoO}_{2}$ cathodes with and without surface coatings. ${ }^{3,4,7,8,20,28,61,62}$ After each charge step, the cell was put to rest for $10 \mathrm{~min}$ followed by the discharge step. Cyclic voltammetry was carried out between 3.6 and $4.2 \mathrm{~V}$ at various scan rates. Electrochemical impedance spectroscopy (EIS) was performed within $1 \mathrm{MHz}$ to $0.1 \mathrm{~Hz}$ range with a $10 \mathrm{mV}$ AC perturbation using a BioLogic VMP-300 system.

\section{RESULTS AND DISCUSSION}

3.1. Structural Characterization. The epitaxial relationship between the $\mathrm{LiCoO}_{2}$ films and the $\mathrm{Nb}$ /strontium titanate
(STO) substrates is shown by the out-of-plane XRD measurements in Figure 1a. Besides the high-intensity sharp peaks from the $\mathrm{Nb} / \mathrm{STO}$ substrates, only peaks belonging to the single crystalline layered $\mathrm{LiCoO}_{2}(R 3 m)$ phase can be observed. For (100)-oriented $\mathrm{Nb} / \mathrm{STO}$ substrates, the epitaxial $\mathrm{LiCoO}_{2}$ layer exhibits a (104) orientation, while for (110)oriented $\mathrm{Nb} / \mathrm{STO}$ substrates, the $\mathrm{LiCoO}_{2}$ layer aligns to the (110) orientation. In contrast, using (111)-oriented $\mathrm{Nb} / \mathrm{STO}$ substrates provides a good match with the in-plane triangular structure of the layered $\mathrm{LiCoO}_{2}$ phase, resulting in alignment of the $\mathrm{LiCoO}_{2}$ layer in the (001) orientation. The successful synthesis of single-crystalline $\mathrm{LiCoO}_{2}$ thin films with specific orientations is in good agreement with observations in previous studies. ${ }^{42-44}$ Although no peaks for other $\mathrm{LiCoO}_{2}$ phases could be observed in the XRD measurements, some contributions of the spinel $\mathrm{LiCoO}_{2}$ phase $(F d \overline{3} m)$ could still be present as it is nearly indistinguishable from the layered $\mathrm{LiCoO}_{2}$ phase $(R 3 m)$. For example, the (100) planes of spinel $\mathrm{LiCoO}_{2}$ are equivalent to the (104) planes of layered $\mathrm{LiCoO}_{2}$, while the (110) planes are also similar in both phases. This is due to a similar oxygen anion framework with ABC-packing which is present in both spinel and layered hexagonal phases. Since $\mathrm{LiCoO}_{2}$ films were grown at $800{ }^{\circ} \mathrm{C}$, the presence of the $\mathrm{Co}_{3} \mathrm{O}_{4}$ phase and lithium deficiency cannot be excluded initially. Therefore, Raman analysis was performed to further distinguish any undesired phases and impurities in the thin films. Figure $1 \mathrm{~b}$ shows the Raman spectra of the $\mathrm{LiCoO}_{2}$ films grown in either the (104) or (001) orientation. Factor group analysis suggests distinct vibrational modes for spinel and layered $\mathrm{LiCoO}_{2}$ phases. ${ }^{63,64}$ The spinel $\mathrm{LiCoO}_{2}(F d \overline{3} m)$ phase exhibits four Raman active bands, attributed to, respectively, $A_{1 g}, E_{g}$, and two $F_{2 g}$ modes. On the other hand, the layered $\mathrm{LiCoO}_{2}(R 3 m)$ phase exhibits only two Raman active bands, attributed to, respectively, $\mathrm{A}_{1 \mathrm{~g}}$ and $\mathrm{E}_{\mathrm{g}}$ modes. The highfrequency mode is assigned to $\mathrm{Co}-\mathrm{O}$ stretching in $\mathrm{CoO}_{6}$ octahedra, whereas the low-frequency mode is assigned to $\mathrm{O}-$ $\mathrm{Co}-\mathrm{O}$ bending. ${ }^{63,65}$ Figure $1 \mathrm{~b}$ shows that in the spectra for both oriented $\mathrm{LiCoO}_{2}$ films, only two strong Raman bands were observed at 484 and $594 \mathrm{~cm}^{-1}$, which confirms that the $\mathrm{LiCoO}_{2}$ films grown by PLD exhibit the layered structure with space group $\mathrm{R} 3 \mathrm{~m}$. The distinct increase in the intensity of the $A_{1 g}$ mode for the (001)-oriented $\mathrm{LiCoO}_{2}$ film suggests an 
enhancement in $\mathrm{Co}-\mathrm{O}$ stretching as expected for the epitaxial in-plane alignment of the $\mathrm{CoO}_{2}$ layers. The additional minor peak at around $659 \mathrm{~cm}^{-1}$ suggests the presence of some traces of the $\mathrm{Co}_{3} \mathrm{O}_{4}$ impurity phase. ${ }^{66}$ ICP-OES analysis was performed to quantify the lithium to cobalt ratio in the $\mathrm{LiCoO}_{2}$ films, which was $0.982 \pm 0.06$ and $0.940 \pm 0.06$ for, respectively, the (104)-oriented and (001)-oriented $\mathrm{LiCoO}_{2}$ films. This confirms that the excess of lithium in the initial target is able to compensate for the loss of lithium during the PLD process caused by the volatility of lithium atoms.

To investigate the effect of a conductive coating, a cubic $\mathrm{TiO}$ film was subsequently in situ deposited on top of the (104)oriented $\mathrm{LiCoO}_{2}$ film. The epitaxial relation between the TiO and $\mathrm{LiCoO}_{2}$ layers was evaluated by out-of-plane XRD analysis, as shown in Figure 2. The cubic (100)-oriented

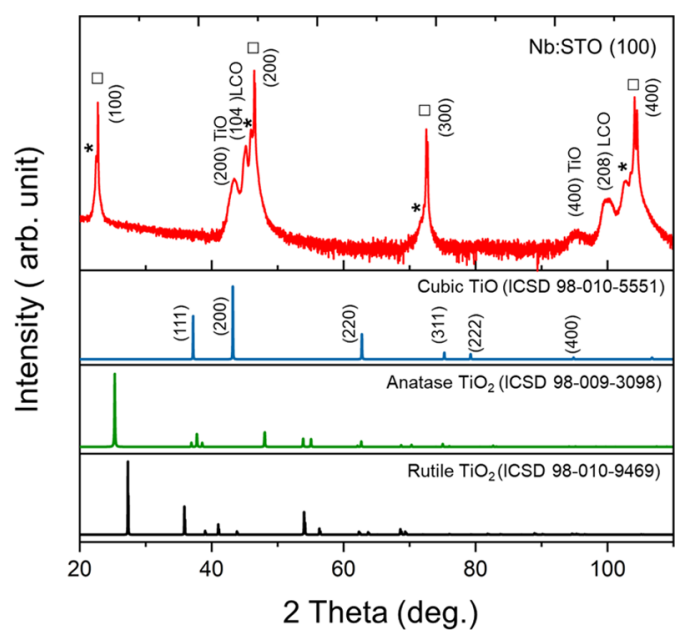

Figure 2. Out-of-plane XRD pattern of epitaxially stabilized (100)oriented cubic $\mathrm{TiO}$ grown on top of a (104)-oriented $\mathrm{LiCoO}_{2}$ thin film. For comparison, the reference diffraction patterns for cubic $\mathrm{TiO}$, anatase $\mathrm{TiO}_{2}$, and rutile $\mathrm{TiO}_{2}$ are also included. $\mathrm{Nb} / \mathrm{SrTiO}_{3}$ and $\mathrm{SrRuO}_{3}$ peaks are indicated by $\square$ and $*$ symbols, respectively.

TiO layer was epitaxially stabilized on the (104)-oriented $\mathrm{LiCoO}_{2}$ layer as only two distinct diffraction peaks at 43.2 and $94.5^{\circ}$, ascribed to (200) and (400) reflections of the cubic $\mathrm{TiO}$ phase, respectively, can be observed besides the characteristic peaks for the (104)-oriented $\mathrm{LiCoO}_{2}$ phase on top of a $\mathrm{SrRuO}_{3}$-buffered $\mathrm{Nb} / \mathrm{STO}(100)$ substrate. The absence of any additional diffraction peaks confirms that the cubic $\mathrm{TiO}$ phase is completely stabilized and free from anatase or rutile phases. The epitaxial growth of cubic TiO (where $a=4.18 \AA$, Ti-Ti = $4.18 \AA, \mathrm{O}-\mathrm{O}=4.18 \AA$ ) is facilitated by the underlying cubic surface arrangement of lithium and cobalt atoms ( $\mathrm{Li}-\mathrm{Co}=$ $4.06 \AA$ ) in the (104) plane of $\mathrm{LiCoO}_{2}$ with a $45^{\circ}$ in-plane rotation with respect to the (200) plane of $\mathrm{TiO}$, as schematically shown in Figure 3. The lattice strain across the $(200) \mathrm{TiO} / /(104) \mathrm{LiCoO}_{2}$ interface is $2.9 \%$, which is similar to the epitaxial match at the underlying (104) $\mathrm{LiCoO}_{2} / /(100)$ $\mathrm{SrRuO}_{3}$ interface (where $\mathrm{Li}-\mathrm{Co}=4.06 \AA$ and $\mathrm{Sr}-\mathrm{Sr}=3.91 \AA$ ) exhibiting a lattice strain of $3.7 \%$. The surface morphology of the noncoated and $\mathrm{TiO}$-coated (104)-oriented $\mathrm{LiCoO}_{2}$ thin films were characterized by AFM, as shown in Figure $4 a, b$ respectively. The (104)-oriented $\mathrm{LiCoO}_{2}$ films exhibit a morphology with trenches in between the cubic structures (rms: $\sim 20 \mathrm{~nm}$ ), which is in good agreement with previous studies. ${ }^{42-44}$ The subsequently deposited $\mathrm{TiO}$ layer forms into 20-30 nm-sized grains on top of the (104)-oriented $\mathrm{LiCoO}_{2}$ surface. The $\mathrm{TiO}$ layer induces an increase in the surface roughness on top of the cubic structures, from a smooth (104)oriented $\mathrm{LiCoO}_{2}$ surface (rms: $\sim 0.3 \mathrm{~nm}$ ) to a grainy (200)oriented $\mathrm{TiO}$ surface (rms: $\sim 4.0 \mathrm{~nm}$ ); see Supporting Information, Figure S1. The structural ordering within the full $\mathrm{TiO}-\mathrm{LiCoO}_{2}-\mathrm{SrRuO}_{3}-\mathrm{Nb} / \mathrm{SrTiO}_{3}$ stack was investigated by scanning electron microscopy (SEM) analysis, as shown in Figure 4c. The layer thicknesses of the $\mathrm{SrRuO}_{3}$ transport layer and the $\mathrm{TiO}$ coating layer were confirmed to be, respectively, 60 and $30 \mathrm{~nm}$. The surface morphology of the (104)-oriented $\mathrm{LiCoO}_{2}$ cathode layer was clearly observed, and an average layer thickness of $120 \mathrm{~nm}$ was determined, in good agreement with the $\mathrm{LiCoO}_{2}$ growth rate previously determined for low surface roughness (001)-oriented $\mathrm{LiCoO}_{2}$ layers (not shown).

3.2. Electrochemical Characterization. The impact of the applied $\mathrm{TiO}$ coating on the electrochemical performance of (a)

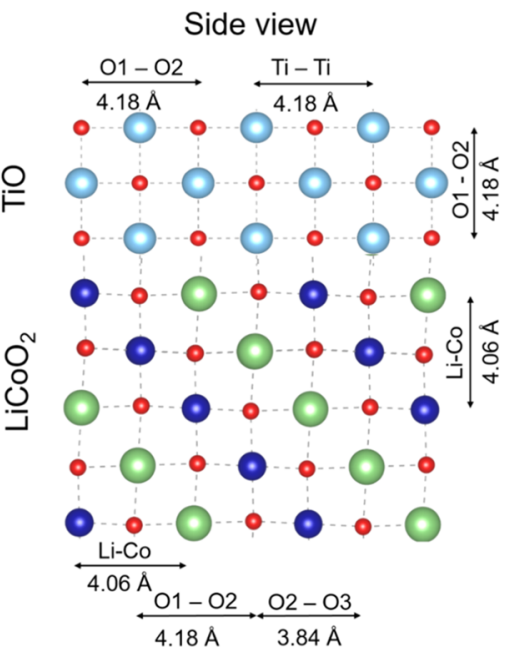

(b)

\section{Top view}

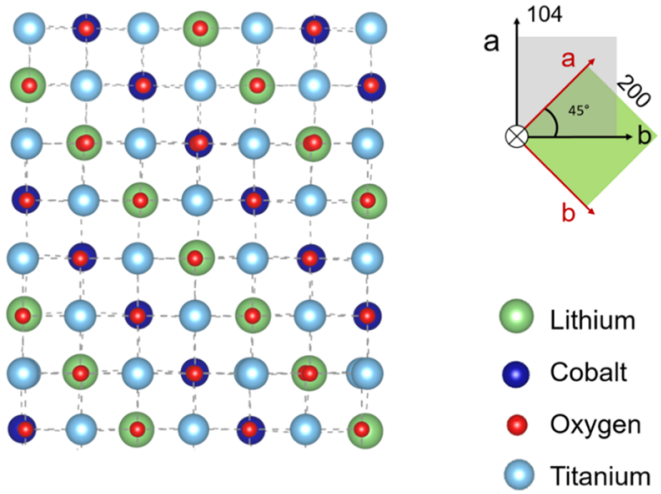

Figure 3. Schematic (a) side view and (b) top view of the atomic arrangement across the epitaxial interface between the (200) TiO and (104) $\mathrm{LiCoO}_{2}$ planes. 
(a)

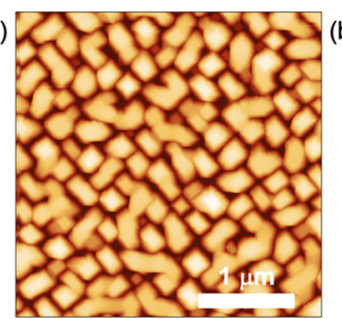

(c)

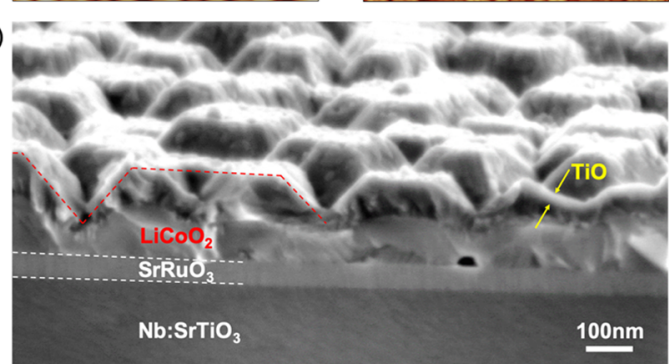

Figure 4. AFM analysis of the surface morphology of (a) bare (104)oriented $\mathrm{LiCoO}_{2}$ thin film and (b) TiO-coated (104)-oriented $\mathrm{LiCoO}_{2}$ thin film. (c) SEM analysis of cross-section showing the structural ordering within the full $\mathrm{TiO}-\mathrm{LiCoO}_{2}-\mathrm{SrRuO}_{3}-\mathrm{Nb} /$ $\mathrm{SrTiO}_{3}$ stack.

the $\mathrm{LiCoO}_{2}$ cathode thin film was investigated through charge-discharge cycling under galvanostatic conditions. The discharge profiles during prolonged cycling at $5 \mathrm{C}$ (keeping charge rate fixed to $1 \mathrm{C}$ rate) of the $\mathrm{TiO}$-coated and noncoated $\mathrm{LiCoO}_{2}$ films are shown in Figure 5a,b respectively. The presence of the characteristic voltage plateau at $\sim 3.9 \mathrm{~V}$ for both $\mathrm{LiCoO}_{2}$ films confirms that the $\mathrm{TiO}$ coating remains electrochemically inactive within the used voltage range (3.5$4.2 \mathrm{~V})$. Interestingly, the noncoated $\mathrm{LiCoO}_{2}$ film shows a slightly higher capacity with a shorter voltage plateau as compared to the TiO-coated $\mathrm{LiCoO}_{2}$ film. This can be attributed to an interfacial pseudo capacitance arising from electrolyte reactivity with the bare $\mathrm{LiCoO}_{2}$ surface. ${ }^{\mathrm{I}}$ The capacity of the noncoated $\mathrm{LiCoO}_{2}$ film reduces significantly faster during cycling than that of the $\mathrm{TiO}$-coated $\mathrm{LiCoO}_{2}$ most likely due to the continuous cation dissolution into the electrolyte as well as the formation of a SEI layer at the $\mathrm{LiCoO}_{2}$ interface with the liquid electrolyte. The difference in cycle life between both cases can be clearly observed in Figure 6 a, which shows that the capacity of $\mathrm{TiO}$-coated $\mathrm{LiCoO}_{2}$ is still $92 \%$ after 200 cycles, in sharp contrast with $67 \%$ for the noncoated $\mathrm{LiCoO}_{2}$.
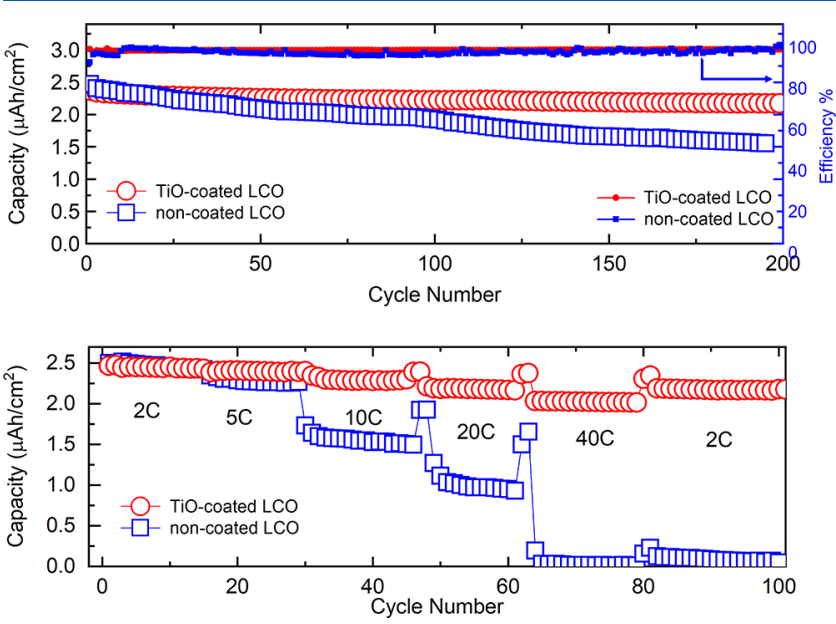

Figure 6. Electrochemical analysis of (top) rate capability at $5 \mathrm{C}$ and (bottom) cycle life of the discharge capacity at various rates determined for TiO-coated and noncoated (104)-oriented LCO films.

The applied cubic (100)-oriented TiO layer is expected to provide an enhancement of the surface passivation (to minimize the SEI formation and structural degradation) as well the ionic transport of lithium between the liquid electrolyte and $\mathrm{LiCoO}_{2}$ cathode. The effect of the $\mathrm{TiO}$ coating on the high rate capability of the test cells was studied between 2 and $40 \mathrm{C}$, as shown in Figure $6 \mathrm{~b}$. As observed before, the TiO-coated and noncoated $\mathrm{LiCoO}_{2}$ films show very similar capacities when cycled at 2 and $5 \mathrm{C}$. However, as the $\mathrm{C}$ rate increases from 10 to $40 \mathrm{C}$, the capacity of noncoated $\mathrm{LiCoO}_{2}$ drops significantly $\left(5 \mathrm{C}=2.31 \mu \mathrm{A} \mathrm{h} / \mathrm{cm}^{2}, 10 \mathrm{C}=1.56 \mu \mathrm{A} \mathrm{h} /\right.$

(a)

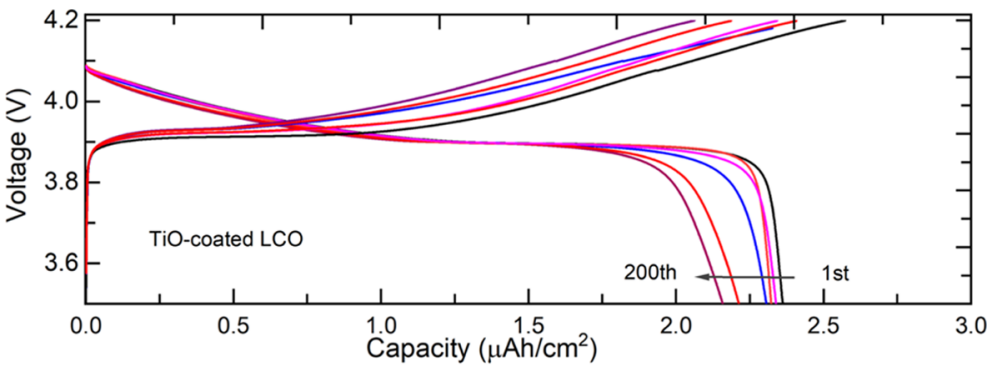

(b)

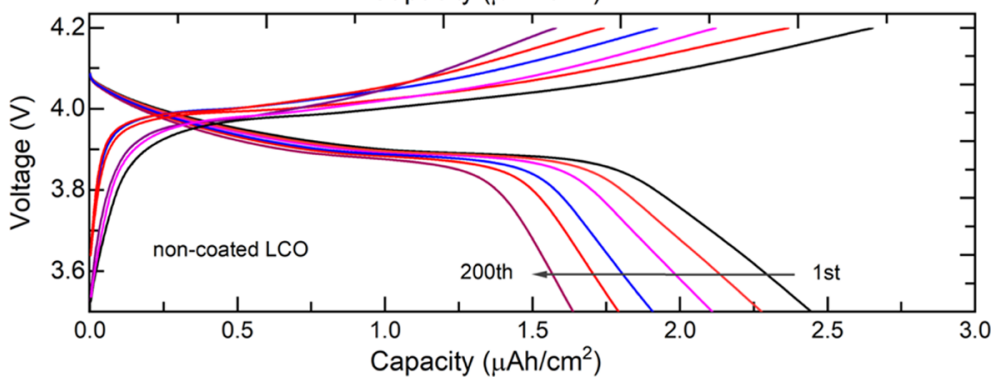

Figure 5. Charge-discharge analysis of (a) TiO-coated and (b) noncoated (104)-oriented LCO films during prolonged cycling at rates of $1 \mathrm{C}$ (during charge) and $5 \mathrm{C}$ (during discharge). 
(a)

(b)

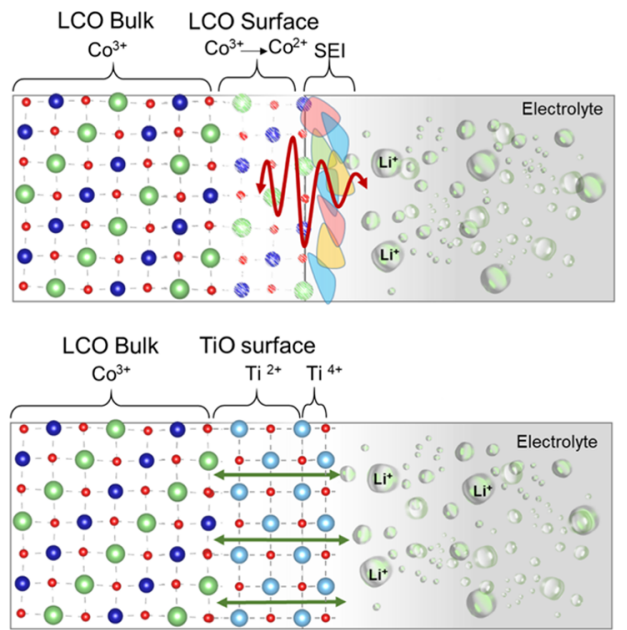

(c)

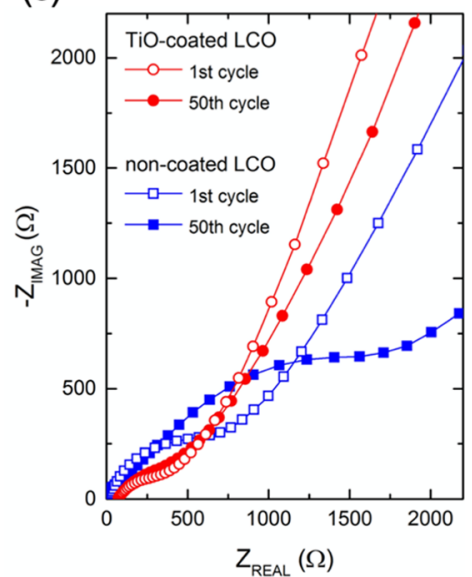

Figure 7. Schematic showing mechanistic insights of surface passivation and lithium transport across electrode-electrolyte interface in (a) noncoated and (b) TiO-coated (104)-oriented LCO thin-film electrodes. (c) EIS analysis of (104)-oriented LCO thin-film electrodes with and without a $\mathrm{TiO}$ coating in the discharge state after the 1 st and 50th charge-discharge cycle at $5 \mathrm{C}$ in $3.5-4.2 \mathrm{~V}$ range.

(a)

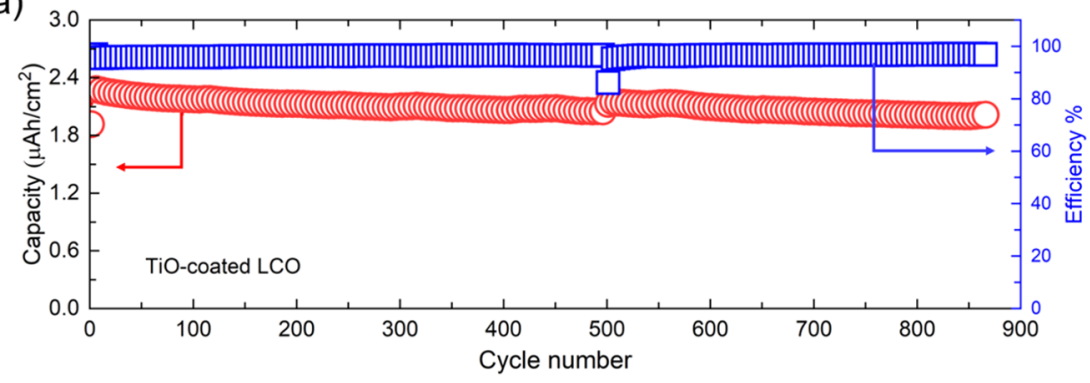

(b)

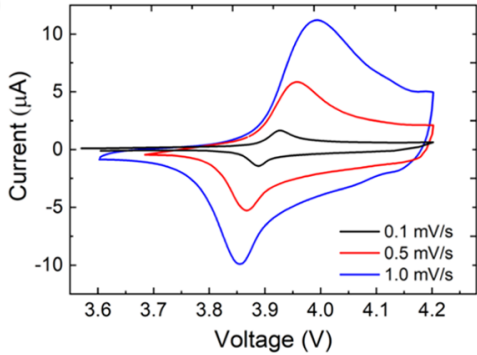

(c)

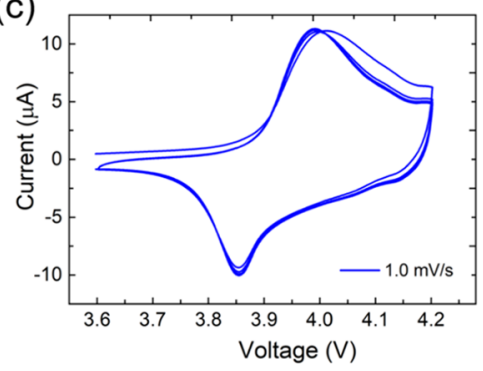

Figure 8. (a) Cycle life analysis of capacity and Coulombic efficiency during prolonged cycling at $5 \mathrm{C}$ for TiO-coated (104)-oriented LCO thin films. Cyclic voltammogram of TiO-coated $\mathrm{LiCoO}_{2}$ thin films (b) prior to cycle life test and (c) after 500 charge-discharge cycles.

$\left.\mathrm{cm}^{2}, 20 \mathrm{C}=1.07 \mu \mathrm{A} \mathrm{h} / \mathrm{cm}^{2}\right)$ and becomes almost zero at $40 \mathrm{C}$. This poor rate and cycle performance is typical for bare $\mathrm{LiCoO}_{2}$ surfaces and can be attributed to surface degradation and unfavorable electrode-electrolyte reactions caused by high oxygen reduction and evolution reactions manifested by the presence of high and intermediate spin $\mathrm{Co}^{3+}$ at the (104) $\mathrm{LiCoO}_{2}$ surface. $^{67}$ These reactions cause the formation of a SEI layer, as schematically shown in Figure $7 \mathrm{a}$, which increases the interfacial resistance during subsequent charge-discharge cycles and limits the rate and cycling performance. In contrast, the $\mathrm{TiO}$-coated $\mathrm{LiCoO}_{2}$ films show remarkable enhanced cycling and rate performance $\left(5 \mathrm{C}=2.33 \mu \mathrm{A} \mathrm{h} / \mathrm{cm}^{2}, 10 \mathrm{C}=\right.$ $2.25 \mu \mathrm{A} \mathrm{h} / \mathrm{cm}^{2}, 20 \mathrm{C}=2.10 \mu \mathrm{A} \mathrm{h} / \mathrm{cm}^{2}$, and $40 \mathrm{C}=1.95 \mu \mathrm{A} \mathrm{h}$ $\mathrm{cm}^{2}$ ) as compared to noncoated $\mathrm{LiCoO}_{2}$. Although the capacity also decreases with increasing $\mathrm{C}$ rate, the overall reduction is rather limited as compared to that in noncoated $\mathrm{LiCoO}_{2}$ and a significant amount of initial capacity is recovered by final cycling at $2 \mathrm{C}$. Furthermore, the cubic (100)-oriented
TiO layer clearly exhibits good lithium-ion transport behavior, as was expected for the open cubic structure providing a large number of interstitial sites for lithium diffusion. ${ }^{50-52}$ In comparison, the commonly used metal oxide coatings (e.g., $\mathrm{TiO}_{2}, \mathrm{Al}_{2} \mathrm{O}_{3}$ ) do not provide such high rate capability due to the close-packed nature of the crystal structures with lower lithium diffusivity. ${ }^{19,48,68,69}$ Therefore, the improved electrochemical performance is attributed to the combination of effective stabilization of the $\mathrm{Co}^{3+}$ state at the $\mathrm{LiCoO}_{2}$ surface with the optimized pathway through the $\mathrm{TiO}$ layer for lithium diffusion, as schematically shown in Figure $7 \mathrm{~b}$. The effect of the $\mathrm{TiO}$ coating on the electrochemical performance was investigated by EIS analysis for (104)-oriented $\mathrm{LiCoO}_{2}$ (LCO) thin-film electrodes with and without a $\mathrm{TiO}$ coating in the discharge state after the 1st and 50th charge-discharge cycle at $5 \mathrm{C}$ in 3.5-4.2 V range; see Figure 7c. The noncoated LCO film exhibits a much higher initial resistance after the 1st cycle as compared to the TiO-coated LCO film, which suggests a 
(a)

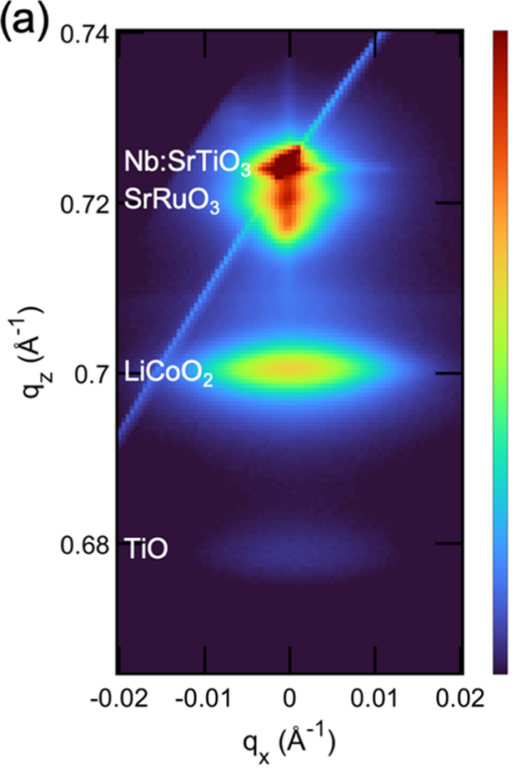

(b)

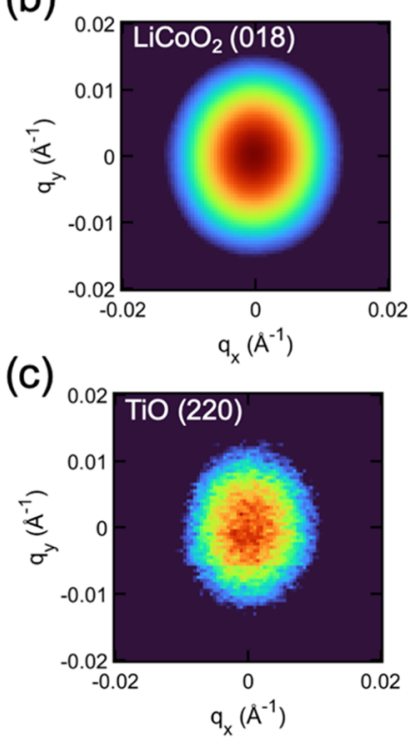

(d)

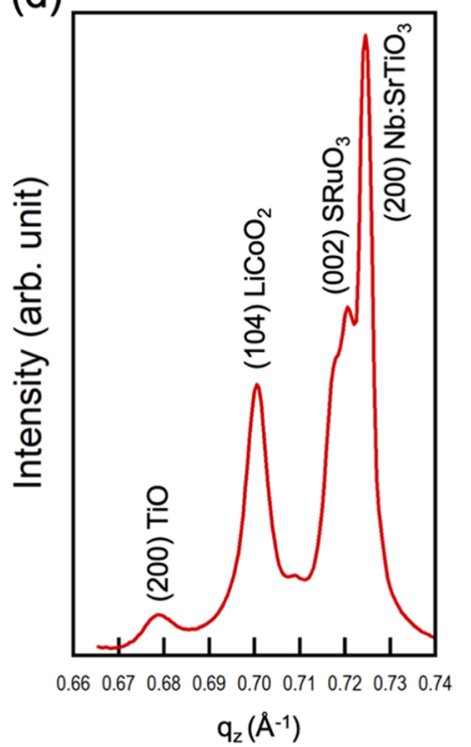

Figure 9. XRD after extensive electrochemical cycling (900 cycles for 3.5-4.2 V range at 5 C). Non-coplanar RSMs measured in skew geometry ( $\psi$ $=45^{\circ}$ ) around the $(220)$ reflection of the $\mathrm{Nb} / \mathrm{SrTiO}_{3}(100)$ substrate. (a) Out-of-plane ( $\mathrm{H}-\mathrm{L}$ ) projection displaying only the four expected sharp reflections for $\mathrm{Nb} / \mathrm{SrTiO}_{3}(220), \mathrm{SrRuO}_{3}(220)_{\mathrm{po}}, \mathrm{LiCoO}_{2}(018)$, and $\mathrm{TiO}(220)$, confirming the epitaxial nature of the layer system with very low out-of-plane crystallographic tilt. (b,c) In-plane projection $(\mathrm{H}-\mathrm{K})$ of $\mathrm{LiCoO}_{2}(018)$ reflection and TiO(220), respectively. The well-defined circular spots attest to a minimal in-plane mosaic twist. (d) Extracted line profile along $q_{z}$ showing reflections corresponding to TiO(200), LiCoO ${ }_{2}(104)$, $\mathrm{SrRuO}_{3}(002)$, and $\mathrm{Nb} / \mathrm{SrTiO}_{3}(200)$.

reaction between the liquid electrolyte and $\mathrm{LiCoO}_{2}$ surface leading to the formation of a CEI layer. During subsequent cycling, the noncoated LCO shows a dramatic increase in resistance, as shown after the 50th cycle, which is in good agreement with the known surface degradation and unfavorable electrode-electrolyte reactions for noncoated $\mathrm{LiCoO}_{2}$ surfaces responsible for the poor rate and cycle performance. However, the TiO-coated LCO shows a very minimal change in resistance after 50 charge-discharge cycles, indicating enhanced surface stability and optimal lithium diffusion through the $\mathrm{TiO}$ coating, enabling very stable, reversible (de)lithiation of the $\mathrm{LiCoO}_{2}$ electrode. Further EIS measurements and modeling will be performed in a future study to explore the detailed electrochemistry in this material system.

The excellent cycle life performance of the TiO-coated $\mathrm{LiCoO}_{2}$ film was investigated in detail during prolonged cycling at a $5 \mathrm{C}$ rate; see Figure $8 \mathrm{a}$. The condition of the $\mathrm{LiCoO}_{2}$ cathode was evaluated through cyclic voltammetry prior to the cycle life test as well as after 500 cycles, as shown in Figure $8 b, c$, respectively. The presence of the characteristic cathodic peak at $3.95 \mathrm{~V}$ and the anodic peak at $3.87 \mathrm{~V}$ suggests that the $\mathrm{LiCoO}_{2}$ film remains close to its pristine condition. When the scan rate increases from 0.1 to $1.0 \mathrm{mV} / \mathrm{s}$ in subsequent cycles, the characteristic peaks shift due to enhanced polarization associated with charge-discharge cycling. After 500 charge-discharge cycles, the successive $\mathrm{CV}$ measurements show similar cathodic and anodic peak positions as compared to the initial $\mathrm{CV}$ measurement indicating good reversibility and cycling stability of the TiOcoated $\mathrm{LiCoO}_{2}$ electrode. At the end of 900 cycles, the TiOcoated $\mathrm{LiCoO}_{2}$ film still exhibited $\sim 80 \%\left(\sim 1.95 \mu \mathrm{A} \mathrm{h} \mathrm{cm}^{-2}\right)$ of its initial capacity, while the Coulombic efficiency remained above $99.9 \%$ throughout the complete cycle life analysis. Selected charge-discharge profiles for the 100th, 500th, and 900th cycles are shown in Supporting Information, Figure S2.
After cycling, the cell was disassembled in a glovebox, the liquid electrolyte was removed, and the $\mathrm{TiO}$-coated $\mathrm{LiCoO}_{2}$ film was analyzed using high-resolution XRD and SEM analysis to confirm the structural integrity throughout prolonged cycling. SEM analysis showed a surface morphology after extensive cycling (Supporting Information, Figure S3) very similar to the pristine surface of the as-deposited sample (Figure 4c), indicating preservation of the good contact between all layers without any exfoliation or crack formation.

High-resolution XRD data were collected post cycling to determine the structural integrity of all layers after extensive charge-discharge cycling, as well as to confirm the epitaxial relation between the layers and the underlying substrate. Here, we present a RSM measured in skew-geometry, that is, noncoplanar, with $\psi=45^{\circ}$ sample tilt, around the (022) reflection of the substrate; see Figure 9a. The processed 3D data set is integrated along the $q_{y}$ (also known as $\mathrm{K}$ ) axis to produce a $2 \mathrm{D}$ out-of-plane $q_{x}-q_{z}$ RSM (also known as an H-L map). Whereas a polycrystalline thin film with randomly oriented grains would show a continuous circular arc around the center of the reciprocal space, that is, a projection of a DebyeScherrer ring; here, we observe well-defined, narrow spots for all three thin-film layers, $\mathrm{SrRuO}_{3}, \mathrm{LiCoO}_{2}$, and $\mathrm{TiO}$, reflecting low mosaic tilt. Additionally, in-plane $q_{x}-q_{y}$ RMSs (also known as $\mathrm{H}-\mathrm{K}$ maps) were made via projection and piecewise integration along the $q_{z}$ axis and analyzed to further confirm the in-plane epitaxial nature of all samples; see Figure 9b,c. Textured films with preferential out-of-plane orientation, but without in-plane order, would show a ring feature in such a plot, which clearly we do not observe. Instead, we find welldefined, symmetrical spots attesting to minimal mosaic twist. Thus, we can exclude with certainty that these thin films are polycrystalline. Furthermore, we measured phi scans of suitable, that is, non-coplanar, $\mathrm{Nb} / \mathrm{SrTiO}_{3}, \mathrm{LiCoO}_{2}$, and $\mathrm{TiO}$ reflections and observed the expected fourfold symmetry 
dictated by the substrate (Figure 10). The narrow shape of the peaks and the absence of intensity in between confirms that the

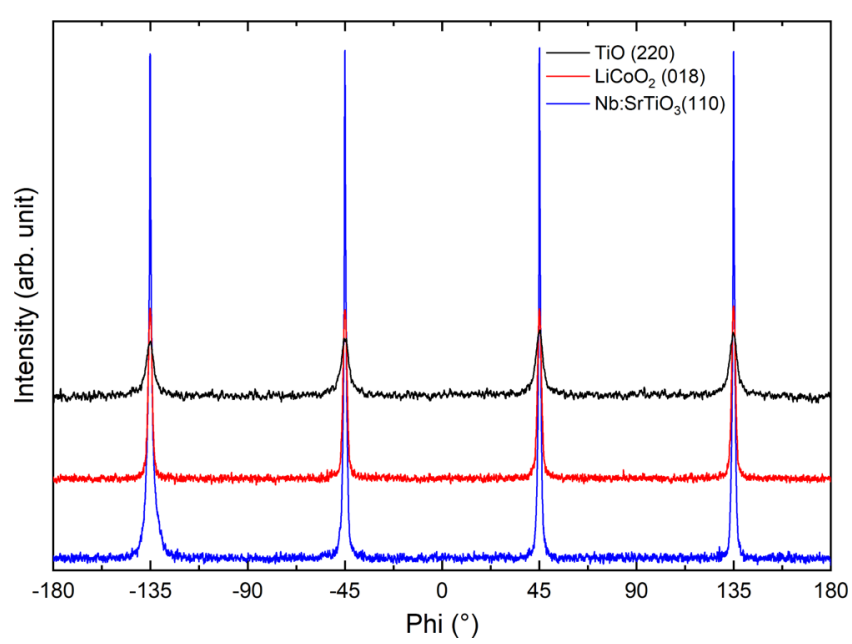

Figure 10. XRD after extensive electrochemical cycling ( 900 cycles for 3.5-4.2 $\mathrm{V}$ range at $5 \mathrm{C}$ ). Phi scans of $\mathrm{LiCoO}_{2}(018)$ and $\mathrm{TiO}(220)$ reflections shown in the RSMs, revealing the expected 4-fold symmetry of the epitaxial layer system in full registry with the single crystalline $\mathrm{Nb}-\mathrm{SrTiO}_{3}$ substrate, confirming minimal mosaic twist.

layers are grown in full registry with the substrate. We note that the epitaxial relation between $\mathrm{LiCoO}_{2}$ and $\mathrm{Nb} / \mathrm{SrTiO}_{3}$ observed here confirms earlier studies by Nishio et al. ${ }^{44}$ Furthermore, out of plane XRD analysis (Figure S4) shows that no additional or impurity phases were detected in cycled TiO-coated $\mathrm{LiCoO}_{2}$ film. However, the possible formation of a very thin fully oxidized $\mathrm{TiO}_{2}$ layer at the (100) TiO surface in contact with the liquid electrolyte cannot be excluded. These post cycling XRD results unequivocally confirm that the $\mathrm{SrRuO}_{3}, \mathrm{LiCoO}_{2}$, and $\mathrm{TiO}$ layers are epitaxially related to the underlying $\mathrm{Nb} / \mathrm{SrTiO}_{3}$ substrate, and this high degree of structural order is preserved over about a thousand charge and discharge cycles.

\section{CONCLUSIONS}

Epitaxial engineering is applied to stabilize a cubic (100)oriented $\mathrm{TiO}$ layer on top of single (104)-oriented $\mathrm{LiCoO}_{2}$ thin films to study the effect of an ionically and electronically conductive coating. Lattice matching between the (104) $\mathrm{LiCoO}_{2}$ surface facets and the (100) TiO plane is crucial to enable the formation of the titanium mono-oxide phase. The application of a cubic $\mathrm{TiO}$ coating dramatically enhances the electrochemical performance of $\mathrm{LiCoO}_{2}$ thin films. This enhanced electrochemical performance combined with post cycling XRD analysis clearly indicates that such cubic TiO coating enhances the preservation of the phase and structural stability across the (104) $\mathrm{LiCoO}_{2}$ surface. The results suggest a more stable $\mathrm{Co}^{3+}$ oxidation state, which not only limits the cobalt-ion dissolution into the electrolyte but also suppresses the catalytic degradation of the liquid electrolyte., 97 Furthermore, the high c-rate performance combined with high Columbic efficiency indicates that interstitial sites in the cubic $\mathrm{TiO}$ lattice offer facile pathways for fast lithium-ion transport.

Detailed analysis in a half cell against lithium metal has shown a dramatic enhancement of the cycling stability as well as the rate capability. The results indicate that $\mathrm{TiO}$ remains electrochemically inactive within the used voltage window $(3.5-4.2 \mathrm{~V})$ and does not contribute to the overall capacity. However, operando spectroscopic studies are required to probe the role of the cubic $\mathrm{TiO}$ coating, and a possible gradient of the $\mathrm{O} / \mathrm{Ti}$ ratio, ${ }^{70}$ when exposed to a liquid electrolyte and its interface to the buried $\mathrm{LiCoO}_{2}$ electrode during consecutive lithium (de)intercalations to build in-depth understanding about the interfacial reactions within such lithium-ion batteries.

\section{ASSOCIATED CONTENT}

\section{SI Supporting Information}

The Supporting Information is available free of charge at https://pubs.acs.org/doi/10.1021/acsaem.1c00603.

AFM surface roughness analysis of noncoated and TiOcoated (104)-oriented $\mathrm{LiCoO}_{2}$ electrode films; galvanostatic charge-discharge profile at $5 \mathrm{C}$ rate for $\mathrm{TiO}$-coated $\mathrm{LiCoO}_{2}(104)$ films; SEM image of the surface of a TiOcoated (104)-oriented $\mathrm{LiCoO}_{2}$ electrode; magnified view of the stable surface morphology after prolonged cycling; and out-of-plane XRD pattern of $\mathrm{TiO}$-coated (104)-oriented $\mathrm{LiCoO}_{2}$ epitaxial thin films (PDF)

\section{AUTHOR INFORMATION}

\section{Corresponding Authors}

Deepak P. Singh - Faculty of Science and Technology, University of Twente, 7500 AE Enschede, Netherlands; ○ orcid.org/0000-0003-1091-8790; Email: d.p.singh@ utwente.nl

Mark Huijben - Faculty of Science and Technology, University of Twente, 7500 AE Enschede, Netherlands; 10 orcid.org/ 0000-0001-8175-6958; Email: m.huijben@utwente.nl

\section{Authors}

Yorick A. Birkhölzer - Faculty of Science and Technology, University of Twente, 7500 AE Enschede, Netherlands; (1) orcid.org/0000-0003-3133-2481

Daniel M. Cunha - Faculty of Science and Technology, University of Twente, 7500 AE Enschede, Netherlands

Thijs Dubbelink - Faculty of Science and Technology, University of Twente, 7500 AE Enschede, Netherlands

Sizhao Huang - Faculty of Science and Technology, University of Twente, 7500 AE Enschede, Netherlands

Theodoor A. Hendriks - Faculty of Science and Technology, University of Twente, 7500 AE Enschede, Netherlands

Caroline Lievens - Faculty of Geo-Information Science and Earth Observation, University of Twente, 7500 AE Enschede, Netherlands

Complete contact information is available at:

https://pubs.acs.org/10.1021/acsaem.1c00603

\section{Notes}

The authors declare no competing financial interest.

\section{ACKNOWLEDGMENTS}

D.P.S., D.M.C., T.A.H., and M.H. acknowledge support by The Netherlands Organization for Scientific Research (NWO) under VIDI Grant no. 13456.

\section{REFERENCES}

(1) Li, M.; Lu, J.; Chen, Z.; Amine, K. 30 Years of Lithium-Ion Batteries. Adv. Mater. 2018, 30, 1800561. 
(2) Van der Ven, A.; Aydinol, M. K.; Ceder, G.; Kresse, G.; Hafner, J. First-principles investigation of phase stability in LixCoO2. Phys. Rev. B: Condens. Matter Mater. Phys. 1998, 58, 2975-2987.

(3) Yoon, W.-S.; Kim, K.-B.; Kim, M.-G.; Lee, M.-K.; Shin, H.-J.; Lee, J.-M.; Lee, J.-S.; Yo, C.-H. Oxygen Contribution on Li-Ion Intercalation-Deintercalation in $\mathrm{LiCoO} 2$ Investigated by O K-Edge and Co L-Edge X-ray Absorption Spectroscopy. J. Phys. Chem. B 2002, 106, 2526-2532.

(4) Reed, J.; Ceder, G.; Van Der Ven, A. Layered-to-Spinel Phase Transition in Li x MnO2. Electrochem. Solid-State Lett. 2001, 4, A78A81.

(5) Reimers, J. N.; Dahn, J. R. Electrochemical and In Situ X-Ray Diffraction Studies of Lithium Intercalation in $\mathrm{Li} \times \mathrm{CoO} 2 . J$. Electrochem. Soc. 1992, 139, 2091-2097.

(6) Van der Ven, A.; Ceder, G. Lithium diffusion in layered LixCoO2. Electrochem. Solid-State Lett. 2000, 3, 301-304.

(7) Kikkawa, J.; Terada, S.; Gunji, A.; Nagai, T.; Kurashima, K.; Kimoto, K. Chemical States of Overcharged LiCoO2 Particle Surfaces and Interiors Observed Using Electron Energy-Loss Spectroscopy. J. Phys. Chem. C 2015, 119, 15823-15830.

(8) Laubach, S.; Laubach, S.; Schmidt, P. C.; Ensling, D.; Schmid, S.; Jaegermann, W.; Thißen, A.; Nikolowski, K.; Ehrenberg, H. Changes in the crystal and electronic structure of $\mathrm{LiCoO} 2$ and $\mathrm{LiNiO} 2$ upon $\mathrm{Li}$ intercalation and de-intercalation. Phys. Chem. Chem. Phys. 2009, 11, $3278-3289$.

(9) Faenza, N. V.; Lebens-Higgins, Z. W.; Mukherjee, P.; Sallis, S.; Pereira, N.; Badway, F.; Halajko, A.; Ceder, G.; Cosandey, F.; Piper, L. F. J.; Amatucci, G. G. Electrolyte-Induced Surface Transformation and Transition-Metal Dissolution of Fully Delithiated LiNi0.8Co0.15Al0.05O2. Langmuir 2017, 33, 9333-9353.

(10) Wang, Z.; Huang, X.; Chen, L. Characterization of Spontaneous Reactions of $\mathrm{LiCoO} 2$ with Electrolyte Solvent for Lithium-Ion Batteries. J. Electrochem. Soc. 2004, 151, A1641-A1652.

(11) Becker, D.; Cherkashinin, G.; Hausbrand, R.; Jaegermann, W. Adsorption of Diethyl Carbonate on $\mathrm{LiCoO} 2$ Thin Films: Formation of the Electrochemical Interface. J. Phys. Chem. C 2014, 118, 962967.

(12) Cabana, J.; Kwon, B. J.; Hu, L. Mechanisms of Degradation and Strategies for the Stabilization of Cathode-Electrolyte Interfaces in Li-Ion Batteries. Acc. Chem. Res. 2018, 51, 299-308.

(13) Wu, N.; Zhang, Y.; Guo, Y.; Liu, S.; Liu, H.; Wu, H. Flakelike $\mathrm{LiCoO} 2$ with Exposed $\{010\}$ Facets As a Stable Cathode Material for Highly Reversible Lithium Storage. ACS Appl. Mater. Interfaces 2016, 8, 2723-2731.

(14) Okubo, M.; Hosono, E.; Kim, J.; Enomoto, M.; Kojima, N.; Kudo, T.; Zhou, H.; Honma, I. Nanosize Effect on High-Rate Li-Ion Intercalation in LiCoO2 Electrode. J. Am. Chem. Soc. 2007, 129, $7444-7452$.

(15) Sharifi-Asl, S.; Soto, F. A.; Nie, A.; Yuan, Y.; Asayesh-Ardakani, H.; Foroozan, T.; Yurkiv, V.; Song, B.; Mashayek, F.; Klie, R. F.; Amine, K.; Lu, J.; Balbuena, P. B.; Shahbazian-Yassar, R. FacetDependent Thermal Instability in LiCoO2. Nano Lett. 2017, 17, 2165-2171.

(16) Bates, J. B.; Dudney, N. J.; Neudecker, B. J.; Hart, F. X.; Jun, H. P.; Hackney, S. A. Preferred Orientation of Polycrystalline LiCoO2 Films. J. Electrochem. Soc. 2000, 147, 59-70.

(17) Yabuuchi, N.; Kawamoto, Y.; Hara, R.; Ishigaki, T.; Hoshikawa, A.; Yonemura, M.; Kamiyama, T.; Komaba, S. A Comparative Study of LiCoO2 Polymorphs: Structural and Electrochemical Characterization of O2-, O3-, and O4-type Phases. Inorg. Chem. 2013, 52, 9131-9142.

(18) Ning, F.; Xu, B.; Shi, J.; Wu, M.; Hu, Y.; Ouyang, C. Structural, Electronic, and Li Migration Properties of RE-Doped (RE = Ce, La) LiCoO2 for Li-ion Batteries: A First-Principles Investigation. J. Phys. Chem. C 2016, 120, 18428-18434.

(19) Scott, I. D.; Jung, Y. S.; Cavanagh, A. S.; Yan, Y.; Dillon, A. C.; George, S. M.; Lee, S.-H. Ultrathin Coatings on Nano-LiCoO2 for LiIon Vehicular Applications. Nano Lett. 2011, 11, 414-418.
(20) Dai, X.; Zhou, A.; Xu, J.; Lu, Y.; Wang, L.; Fan, C.; Li, J. Extending the High-Voltage Capacity of $\mathrm{LiCoO} 2$ Cathode by Direct Coating of the Composite Electrode with $\mathrm{Li} 2 \mathrm{CO} 3$ via Magnetron Sputtering. J. Phys. Chem. C 2016, 120, 422-430.

(21) Kim, G.-Y.; Petibon, R.; Dahn, J. R. Effects of Succinonitrile (SN) as an Electrolyte Additive on the Impedance of $\mathrm{LiCoO}$ / Graphite Pouch Cells during Cycling. J. Electrochem. Soc. 2014, 161, A506-A512.

(22) Takamatsu, D.; Orikasa, Y.; Mori, S.; Nakatsutsumi, T.; Yamamoto, K.; Koyama, Y.; Minato, T.; Hirano, T.; Tanida, H.; Arai, H.; Uchimoto, Y.; Ogumi, Z. Effect of an Electrolyte Additive of Vinylene Carbonate on the Electronic Structure at the Surface of a Lithium Cobalt Oxide Electrode under Battery Operating Conditions. J. Phys. Chem. C 2015, 119, 9791-9797.

(23) Lee, K. T.; Jeong, S.; Cho, J. Roles of Surface Chemistry on Safety and Electrochemistry in Lithium Ion Batteries. Acc. Chem. Res. 2013, 46, 1161-1170.

(24) Abe, M.; Iba, H.; Suzuki, K.; Minamishima, H.; Hirayama, M.; Tamura, K.; Mizuki, J. i.; Saito, T.; Ikuhara, Y.; Kanno, R. Study on the deterioration mechanism of layered rock-salt electrodes using epitaxial thin films - $\mathrm{Li}(\mathrm{Ni}, \mathrm{Co}, \mathrm{Mn}) \mathrm{O} 2$ and their $\mathrm{Zr}-\mathrm{O}$ surface modified electrodes. J. Power Sources 2017, 345, 108-119.

(25) Zhao, Y.; Li, J.; Dahn, J. R. Interdiffusion of Cations from Metal Oxide Surface Coatings into LiCoO2 During Sintering. Chem. Mater. 2017, 29, 5239-5248.

(26) Dahéron, L.; Dedryvère, R.; Martinez, H.; Flahaut, D.; Ménétrier, M.; Delmas, C.; Gonbeau, D. Possible Explanation for the Efficiency of Al-Based Coatings on LiCoO2: Surface Properties of LiCo1-xAlxO2 Solid Solution. Chem. Mater. 2009, 21, 5607-5616.

(27) Zhou, A.; Liu, Q.; Wang, Y.; Wang, W.; Yao, X.; Hu, W.; Zhang, L.; Yu, X.; Li, J.; Li, H. Al2O3 surface coating on $\mathrm{LiCoO} 2$ through a facile and scalable wet-chemical method towards highenergy cathode materials withstanding high cutoff voltages. J. Mater. Chem. A 2017, 5, 24361-24370.

(28) Kim, Y. J.; Lee, E.-K.; Kim, H.; Cho, J.; Cho, Y. W.; Park, B.; Oh, S. M.; Yoon, J. K. Changes in the Lattice Constants of Thin-Film LiCoO2 Cathodes at the $4.2 \mathrm{~V}$ Charged State. J. Electrochem. Soc. 2004, 151, A1063-A1067.

(29) Yano, A.; Aoyama, S.; Shikano, M.; Sakaebe, H.; Tatsumi, K.; Ogumi, Z. Surface Structure and High-Voltage Charge/Discharge Characteristics of $\mathrm{Al}$-Oxide Coated $\mathrm{LiNi1} / 3 \mathrm{Co} 1 / 3 \mathrm{Mn} 1 / 3 \mathrm{O} 2$ Cathodes. J. Electrochem. Soc. 2015, 162, A3137-A3144.

(30) Richards, W. D.; Miara, L. J.; Wang, Y.; Kim, J. C.; Ceder, G. Interface Stability in Solid-State Batteries. Chem. Mater. 2016, 28, 266-273.

(31) Sakuda, A.; Hayashi, A.; Tatsumisago, M. Interfacial Observation between $\mathrm{LiCoO} 2$ Electrode and Li2S-P2S5 Solid Electrolytes of All-Solid-State Lithium Secondary Batteries Using Transmission Electron Microscopy. Chem. Mater. 2010, 22, 949-956.

(32) Gittleson, F. S.; El Gabaly, F. Non-Faradaic Li+ Migration and Chemical Coordination across Solid-State Battery Interfaces. Nano Lett. 2017, 17, 6974-6982.

(33) Zhang, W.; Richter, F. H.; Culver, S. P.; Leichtweiss, T.; Lozano, J. G.; Dietrich, C.; Bruce, P. G.; Zeier, W. G.; Janek, J. Degradation Mechanisms at the Li10GeP2S12/LiCoO2 Cathode Interface in an All-Solid-State Lithium-Ion Battery. ACS Appl. Mater. Interfaces 2018, 10, 22226-22236.

(34) Leung, K.; Leenheer, A. How Voltage Drops Are Manifested by Lithium Ion Configurations at Interfaces and in Thin Films on Battery Electrodes. J. Phys. Chem. C 2015, 119, 10234-10246.

(35) Kim, K. H.; Iriyama, Y.; Yamamoto, K.; Kumazaki, S.; Asaka, T.; Tanabe, K.; Fisher, C. A. J.; Hirayama, T.; Murugan, R.; Ogumi, Z. Characterization of the interface between $\mathrm{LiCoO} 2$ and Li7La3Zr2O12 in an all-solid-state rechargeable lithium battery. J. Power Sources 2011, 196, 764-767.

(36) Ohta, N.; Takada, K.; Zhang, L.; Ma, R.; Osada, M.; Sasaki, T. Enhancement of the High-Rate Capability of Solid-State Lithium Batteries by Nanoscale Interfacial Modification. Adv. Mater. 2006, 18, $2226-2229$ 
(37) van den Broek, J.; Afyon, S.; Rupp, J. L. M. InterfaceEngineered All-Solid-State Li-Ion Batteries Based on Garnet-Type Fast Li+ Conductors. Adv. Energy Mater. 2016, 6, 1600736.

(38) Qian, D.; Hinuma, Y.; Chen, H.; Du, L.-S.; Carroll, K. J.; Ceder, G.; Grey, C. P.; Meng, Y. S. Electronic Spin Transition in Nanosize Stoichiometric Lithium Cobalt Oxide. J. Am. Chem. Soc. 2012, 134, 6096-6099.

(39) Ning, F.; Li, S.; Xu, B.; Ouyang, C. Strain tuned Li diffusion in $\mathrm{LiCoO} 2$ material for $\mathrm{Li}$ ion batteries: A first principles study. Solid State Ionics 2014, 263, 46-48.

(40) Moradabadi, A.; Kaghazchi, P. Mechanism of Li intercalation/ deintercalation into/from the surface of LiCoO2. Phys. Chem. Chem. Phys. 2015, 17, 22917-22922.

(41) Rosciano, F.; Pescarmona, P. P.; Houthoofd, K.; Persoons, A.; Bottke, P.; Wilkening, M. Towards a lattice-matching solid-state battery: synthesis of a new class of lithium-ion conductors with the spinel structure. Phys. Chem. Chem. Phys. 2013, 15, 6107-6112.

(42) Li, Z.; Yasui, S.; Takeuchi, S.; Creuziger, A.; Maruyama, S.; Herzing, A. A.; Takeuchi, I.; Bendersky, L. A. Structural study of epitaxial $\mathrm{LiCoO} 2$ films grown by pulsed laser deposition on single crystal $\mathrm{SrTiO} 3$ substrates. Thin Solid Films 2016, 612, 472-482.

(43) Takeuchi, S.; Tan, H.; Bharathi, K. K.; Stafford, G. R.; Shin, J.; Yasui, S.; Takeuchi, I.; Bendersky, L. A. Epitaxial LiCoO2 Films as a Model System for Fundamental Electrochemical Studies of Positive Electrodes. ACS Appl. Mater. Interfaces 2015, 7, 7901-7911.

(44) Nishio, K.; Ohnishi, T.; Akatsuka, K.; Takada, K. Crystal orientation of epitaxial $\mathrm{LiCoO} 2$ films grown on $\mathrm{SrTiO} 3$ substrates. J. Power Sources 2014, 247, 687-691.

(45) Kwon, T.; Ohnishi, T.; Mitsuishi, K.; Ozawa, T. C.; Takada, K. Synthesis of $\mathrm{LiCoO} 2$ epitaxial thin films using a sol-gel method. J. Power Sources 2015, 274, 417-423.

(46) Minato, T.; Kawaura, H.; Hirayama, M.; Taminato, S.; Suzuki, K.; Yamada, N. L.; Sugaya, H.; Yamamoto, K.; Nakanishi, K.; Orikasa, Y.; Tanida, H.; Kanno, R.; Arai, H.; Uchimoto, Y.; Ogumi, Z. Dynamic Behavior at the Interface between Lithium Cobalt Oxide and an Organic Electrolyte Monitored by Neutron Reflectivity Measurements. J. Phys. Chem. C 2016, 120, 20082-20088.

(47) Sumita, M.; Ohno, T. Multi-spin-state at a Li3PO4/LiCoO2

(104) interface. Phys. Chem. Chem. Phys. 2016, 18, 4316-4319.

(48) Yasuhara, S.; Yasui, S.; Teranishi, T.; Chajima, K.; Yoshikawa, Y.; Majima, Y.; Taniyama, T.; Itoh, M. Enhancement of Ultrahigh Rate Chargeability by Interfacial Nanodot BaTiO3 Treatment on LiCoO2 Cathode Thin Film Batteries. Nano Lett. 2019, 19, 16881694

(49) Bartkowski, S.; Neumann, M.; Kurmaev, E. Z.; Fedorenko, V. V.; Shamin, S. N.; Cherkashenko, V. M.; Nemnonov, S. N.; Winiarski, A.; Rubie, D. C. Electronic structure of titanium monoxide. Phys. Rev. B: Condens. Matter Mater. Phys. 1997, 56, 10656-10667.

(50) Banus, M. D.; Reed, T. B.; Strauss, A. J. Electrical and Magnetic Properties of TiO and VO. Phys. Rev. B: Solid State 1972, 5, 27752784.

(51) Goodenough, J. B. Influence of Atomic Vacancies on the Properties of Transition-Metal Oxides. I TiOx and VOx. Phys. Rev. B: Solid State 1972, 5, 2764-2774.

(52) Barman, S. R.; Sarma, D. D. Electronic structure of TiOx $(0.8<\mathrm{x}<1.3)$ with disordered and ordered vacancies. Phys. Rev. B: Condens. Matter Mater. Phys. 1994, 49, 16141-16148.

(53) Hao, Z.; Chen, Q.; Dai, W.; Ren, Y.; Zhou, Y.; Yang, J.; Xie, S.; Shen, Y.; Wu, J.; Chen, W.; Xu, G. Q. Oxygen-Deficient Blue TiO2 for Ultrastable and Fast Lithium Storage. Adv. Energy Mater. 2020, 10, 1903107.

(54) Kubicek, M.; Wachter-Welzl, A.; Rettenwander, D.; Wagner, R.; Berendts, S.; Uecker, R.; Amthauer, G.; Hutter, H.; Fleig, J. Oxygen Vacancies in Fast Lithium-Ion Conducting Garnets. Chem. Mater. 2017, 29, 7189-7196.

(55) Shin, J.-Y.; Joo, J. H.; Samuelis, D.; Maier, J. Oxygen-Deficient $\mathrm{TiO} 2-\delta$ Nanoparticles via Hydrogen Reduction for High Rate Capability Lithium Batteries. Chem. Mater. 2012, 24, 543-551.
(56) Hendriks, R.; Cunha, D. M.; Singh, D. P.; Huijben, M. Enhanced Lithium Transport by Control of Crystal Orientation in Spinel LiMn2O4 Thin Film Cathodes. ACS Appl. Energy Mater. 2018, 1, 7046-7051.

(57) Park, S.-G.; Lee, S.-R.; Cho, W. I.; Cho, B. W. Dependence of $\mathrm{Al} 2 \mathrm{O} 3$ coating thickness and annealing conditions on microstructural and electrochemical properties of $\mathrm{LiCoO} 2$ film. Met. Mater. Int. 2010, $16,93-98$.

(58) Sastre, J.; Chen, X.; Aribia, A.; Tiwari, A. N.; Romanyuk, Y. E. Fast Charge Transfer across the Li7La3Zr2O12 Solid Electrolyte/ LiCoO2 Cathode Interface Enabled by an Interphase-Engineered AllThin-Film Architecture. ACS Appl. Mater. Interfaces 2020, 12, 3619636207.

(59) Kim, Y. J.; Kim, H.; Kim, B.; Ahn, D.; Lee, J.-G.; Kim, T.-J.; Son, D.; Cho, J.; Kim, Y.-W.; Park, B. Electrochemical Stability of Thin-Film LiCoO2 Cathodes by Aluminum-Oxide Coating. Chem. Mater. 2003, 15, 1505-1511.

(60) He, B. B., Two-dimensional X-ray Diffraction, 2nd ed.; Wiley, 2018.

(61) Chen, Z.; Dahn, J. R. Studies of LiCoO[sub 2] Coated with Metal Oxides. Electrochem. Solid-State Lett. 2003, 6, A221.

(62) Paulsen, J. M.; Mueller-Neuhaus, J. R.; Dahn, J. R. Layered LiCoO2 with a Different Oxygen Stacking (O2 Structure) as a Cathode Material for Rechargeable Lithium Batteries. J. Electrochem. Soc. 2000, 147, 508-516.

(63) Huang, W.; Frech, R. Vibrational spectroscopic and electrochemical studies of the low and high temperature phases of LiCo1-x $\mathrm{MxO} 2(\mathrm{M}=\mathrm{Ni}$ or $\mathrm{Ti})$. Solid State Ionics 1996, 86-88, 395-400.

(64) Baddour-Hadjean, R.; Pereira-Ramos, J.-P. Raman Microspectrometry Applied to the Study of Electrode Materials for Lithium Batteries. Chem. Rev. 2010, 110, 1278-1319.

(65) Tintignac, S.; Baddour-Hadjean, R.; Pereira-Ramos, J.-P.; Salot, R. High performance sputtered $\mathrm{LiCoO} 2$ thin films obtained at a moderate annealing treatment combined to a bias effect. Electrochim. Acta 2012, 60, 121-129.

(66) Hadjiev, V. G.; Iliev, M. N.; Vergilov, I. V. The Raman spectra of Co 3 O 4. J. Phys. C: Solid State Phys. 1988, 21, L199.

(67) Han, B.; Qian, D.; Risch, M.; Chen, H.; Chi, M.; Meng, Y. S.; Shao-Horn, Y. Role of LiCoO2 Surface Terminations in Oxygen Reduction and Evolution Kinetics. J. Phys. Chem. Lett. 2015, 6, 13571362.

(68) Qian, J.; Liu, L.; Yang, J.; Li, S.; Wang, X.; Zhuang, H. L.; Lu, Y. Electrochemical surface passivation of $\mathrm{LiCoO} 2$ particles at ultrahigh voltage and its applications in lithium-based batteries. Nat. Commun. 2018, 9, 4918.

(69) Moon, S.-H.; Kim, M.-C.; Kim, E.-S.; Shin, Y.-K.; Lee, J.-E.; Choi, S.; Park, K.-W. TiO2-coated $\mathrm{LiCoO} 2$ electrodes fabricated by a sputtering deposition method for lithium-ion batteries with enhanced electrochemical performance. RSC Adv. 2019, 9, 7903-7907.

(70) Xu, J.; Wang, D.; Yao, H.; Bu, K.; Pan, J.; He, J.; Xu, F.; Hong, Z.; Chen, X.; Huang, F. Nano Titanium Monoxide Crystals and Unusual Superconductivity at 11 K. Adv. Mater. 2018, 30, 1706240. 